\title{
Favouring reflexivity in technology-enhanced learning systems: towards smart uses of traces
}

\author{
Sébastien George $^{\mathrm{a} *}$, Christine Michel $^{\mathrm{b}}$ and Magali Ollagnier-Beldame ${ }^{\mathrm{c}}$ \\ ${ }^{a}$ LUNAM Université, Université du Maine, EA 4023, LIUM, Le Mans 72085, France; ${ }^{b}$ INSA-Lyon, \\ LIRIS, UMR 5205 CNRS, F-69621, Lyon, France; 'ICAR-Interactions, Corpus, Apprentissages, \\ Représentations, UMR 5191, CNRS, Lyon, France
}

\begin{abstract}
During learning activities, reflexive processes allow learners to realise what they have done, understand why, decide on new actions and gain motivation. They help learners to regulate their actions by themselves, that is, to develop metacognitive regulation skills. Computer environments can support reflexive processes to support human learning, for example by analysing traces of learner activity and providing synthetic views by the way of indicators. Nevertheless, traces are underused in technologyenhanced learning (TEL) systems. In this article, we draw up the potential and limits of TEL systems based on traces for reflexive purposes. We then highlight the characteristics which TEL systems should have to use traces to foster reflexivity. We finally discuss how systems could enrich the self-confrontation process with traces.
\end{abstract}

Keywords: interaction traces; technology-enhanced learning; reflexive processes; selfregulation

\section{Introduction}

The field of technology-enhanced learning (TEL) aims at conceiving, creating and evaluating digital environments that aim to initiate and foster human learning (Chan et al., 2006). In this field, social constructivism gave rise to several teaching methods, taking advantage of the relationships between actions, social activities and the ability to reuse experiences through regulation processes to support learning. The most well-known teaching methods are active learning, learning through co-construction and experiential learning. Active learning methods (Bonwell \& Eison, 1991) are based on the fact that learning is deeper when it is an active process in which learners act directly on objects and interact with people, ideas and events, thereby constructing their own understanding of the world. In learning through co-construction methods, learners invest themselves in collective activities and compare or discuss their various contributions (Reusser, 2001). In experiential learning (Kolb, 1984), learning is the result of sense-making "from the world" and interpretation/reinterpretation.

Regulation is used to support:

*Corresponding author. Email: sebastien.george@univ-lemans.fr 
... individual and social processes of adaptation, engagement, participation, learning, and development. Self-regulation focuses on the cognitive and metacognitive regulatory processes used by individuals to plan, enact, and sustain their desired courses of action, whereas social regulation captures how individuals reciprocally regulate each other's cognitive and metacognitive processes and sometimes engage in genuinely shared modes of cognitive and metacognitive regulation. (Volet, Vauras, \& Salonen, 2009, p. 216)

Indeed, constructivist and social constructivist learning theories place the subject at the heart and reveal the importance of learning practices which take themselves as the object, that is, reflexive practices. In his study of professional practices, Schön (1987) showed that reflexive thought is a continuous cognitive process, in which thought loops back onto itself in order to make knowledge appear. A reflexive process allows learners to regulate their actions themselves. The action then becomes the source of knowledge and learning: That is why reflexive practices are usually associated with self-regulated learning strategies.

To favour regulation or self-regulation, it is necessary to observe learner's activity. The usual way to observe activities undertaken with TEL systems is to use traces as a "mirror with a memory." Systems use these traces to analyse user patterns or for pedagogical monitoring. Traces allow regulation effects by peers or tutors and also self-regulation. Traces also help the learners to distance themselves from the activity and allow a reflexive type of awareness to emerge. Given advances in research, it is now possible to encompass traces that have more educational-added value and use them to support self-regulation processes.

Nevertheless, a problem still remains: How can traces be used to promote self-regulation activities? In this article, we wish to specifically study how we can foster reflexive processes made possible by traces, in order to create different kinds of learning platforms, called TEL(T) systems, using both trace-based systems (TBS) and TEL systems. We offer answers to the following two questions: (1) What are the conditions required forTEL(T) systems to smartly use traces?; and (2) What types of human-computer interaction and computer-computer interaction are useful for design and how are they actually proposed in TEL systems?

In the following section we describe how current TEL systems support self-regulation and cognitive reflexive processes by using traces. In Section 3, we analyse their limits regarding reflexive purpose. Our contribution, in Section 4, is a list of requirements to design reflexive TEL systems with a smart use of traces. Finally, the last part of the article discusses how a computer system can contribute to enrich the self-confrontation process by using traces.

\section{TEL systems supporting reflexivity by using traces}

\subsection{Characteristics of TEL systems with reflexive support}

TEL systems with reflexive support belong to two major design streams. Regarding their reflexive targets they can be characterised according to metacognitive principles; regarding their social constructivist philosophy they also refer to computer-supported collaborative learning (CSCL) principles.

Concerning metacognitive tools for learning, Azevedo (2007) identified five characteristics: (1) Learners must make decisions according to defined goals; (2) the learning context should be taken into account when defining teaching strategies; (3) the environment uses technology that amplifies the self-regulation process by considering cognitive and 
metacognitive activity, motivation and behaviour; (4) the environment uses technology to support the learning process through external control provided by a human (tutor, peer, partner) or an intelligent tutoring system (ITS) and finally (5) the environment uses technology in which learners can regulate their activities before, during and after the learning phase, by using self-regulation processes. In this article, we only focus on the three latter characteristics proposed by Azevedo to illustrate how reflexive TEL systems using traces are designed because we only considered traces recording all interactions between the learners and the system.

Furthermore, many regulation strategies are designed according to CSCL principles because reflexive practices arise from social constructivist principles. In Soller, Martinez, Jermann, and Muehlenbrock (2005), the researchers offer a framework to classify the types of support systems for collaborative learning. Distinctions are made between mirroring systems - which give learners raw indicators; indication systems - which outline the state of actions and interactions with a set of indicators as well as interpretation help; and coaching systems - giving advice based on an automatic analysis of these indicators. We have decided to use the term "indication system" rather than "metacognitive system" previously used by Sollers et al. because Azevedo's metacognition tools definition is more precise. This classification is helpful to present how the characteristics (3-5) of the Azevedo classification are taken into account to design TEL regulation with traces. These three types of systems follow a continuum from the human side to the computer side. In the mirroring systems, the review process occurs on the human side (learners, teachers), whereas in coaching systems, the information processing occurs on the computer system side (diagnostic and proposal). Indication systems are situated in the middle of the continuum: The processes of analysing and interpreting the traced data are shared by humans and machines.

\subsubsection{Mirroring systems}

Mirroring systems, also called reflective systems, offer tools that reflect back to learners a certain image of their activity (whether individual or collective). This feedback can occur either during the activity with awareness tools or can take place in a time-differentiated manner where the learners can then go back to the past activity by visualising a more or less detailed history of the activity.

In the collaborative traffic simulator (COTRAS), an awareness tool is used which highlights the mirroring phenomenon (Jermann \& Dillenbourg, 2008) discussed here (in Figure 1). Two

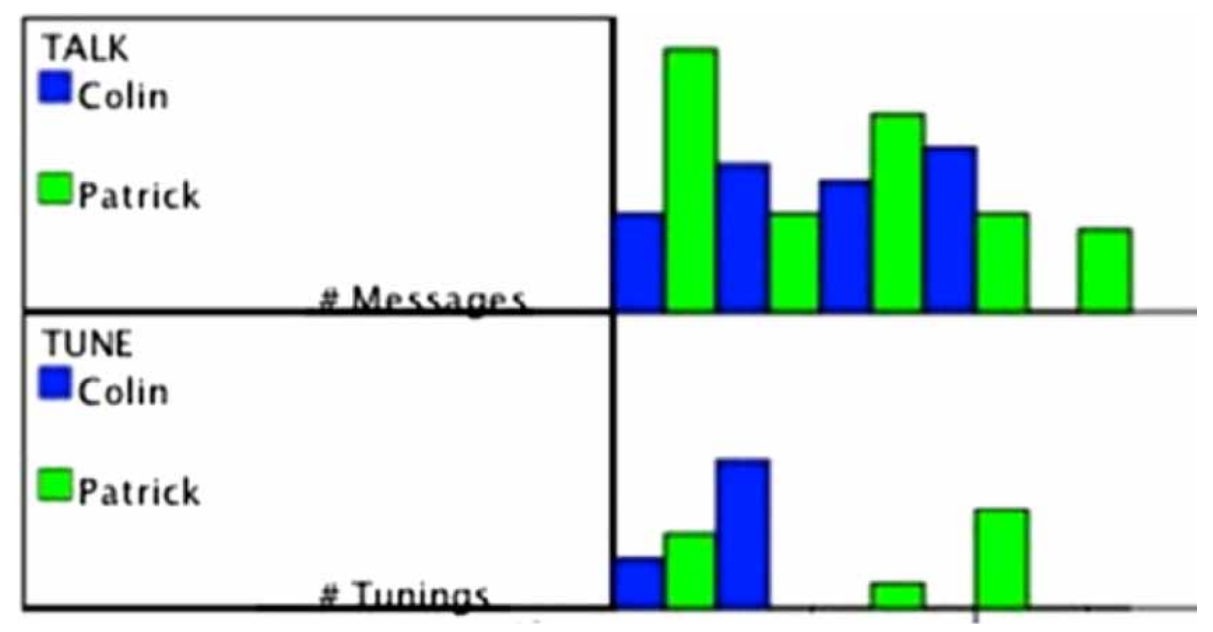

Figure 1. An example of a mirroring tool in COTRAS (Jermann \& Dillenbourg, 2008). 
learners work together to conduct an activity such as regulating road traffic. During the activity, the learners can see graphic representations of their actions simultaneously. In this case, actions are twofold: There are messages in a chat box and adjustments are made to the traffic lights. The representation is actively updated every minute with the addition of a new column. Such a representation complies with a usable visualisation of traces and it explains which learners are involved in the trace activity. ${ }^{1}$ As traces are not interpreted here, learners are responsible for the regulation of their activity from traces. ${ }^{2}$

This type of mirroring tool's clear objective is to give to the learner an image of their behaviour and encourage thinking about such a behaviour. This can, for example, lead the learner to a change in attitude if they realise that such an attitude is inappropriate considering what is expected in the activity.

Another classic example of the mirroring system is software where the activity can be replayed. The learner's activity (individual or collective) is traced and the actions and events that constitute the activity can be replayed after the session. Different functionalities exist such as replaying the activity at different speeds (step by step, in slow motion, faster). Such a visualisation of traces allows learners to act on their traces. ${ }^{3}$ This type of tool, often known as a "replayer" can be useful for the learners to distance themselves from their activity. It can also be useful to synchronise different types of data. For example, by synchronising a video with mediatised discussion events, the attitudes of the different participants during the debate can be highlighted.

\subsubsection{Indication systems}

Indication systems are defined as systems which give feedback to the user, allowing the user to go through certain metacognitive processes: Recognition, evaluation or reflection, as defined by Peña, Kayashima, and Dominguez (2012). When attempting to create a more developed intelligent tutor, these researchers identified seven types of metacognitive regulation: Monitoring, recognition, evaluation, reflection, awareness, adjustment and planning. Recognition consists of highlighting key information about the activity by comparing the monitored information with the information from the cognitive activity model. Evaluation consists in examining the information that serves to measure the progress made by cognitive activity on the base activity, using information taken from the recognition phase. Reflection consists in analysing the evaluations in order to determine the efficiency of the cognitive activity. In indication systems, the elements that allow these processes to take place are generally transmitted to learners; the system does not usually implement them itself.

The most common indication systems are dashboards. Dashboards show which learners are involved in trace activities and they offer a documented confrontation with traces. ${ }^{4}$ Used mainly for work in groups and to complete projects in the professional world, dashboards are meant to concisely and globally present useful information when analysing a situation and when making strategic decisions. In the context of group work, dashboards can be seen as tools supporting mediated cognition (Treude \& Storey, 2010). In the context of learning, they are often used to support the monitoring phase by analysing the interaction traces, as reviewed in the first part of this article. When they are intended to support judgement processes, they integrate information concerning the effective implementation of the activity as well as other pieces of analytical information such as, for example, goals to attain or the learner's judgement calls during the activity, as illustrated in the examples below.

Traces used in these systems are collected either manually or automatically. As an example, the LCC device (Cortez, Nussbaum, Woywood, \& Aravena, 2009) collects 
information manually: Using a personal digital assistant, learners enter the completed tasks and describe the collaboration style within their work group. A real-time display of the information allows learners and tutors to have a full view, as the activity occurs, of the group's progress regarding the accomplishment of tasks and the ways in which group work is completed.

Pco-Vision (Michel, Lavoué, \& Piétrac, 2012) is a dashboard used for learning in the context of a project. With this, the student can see the general vision and the goals/ actions/results needed for self-regulation and the construction of complex skills (such as change in behaviour) in the case of project-based learning. The application's traces are self-declarative (students report on the skills gained, their state of mind, the tasks completed and the work time) and presented concisely, in the form of individual or collective dashboards, as shown on Figure $2 .^{5}$ Indicators, visible during the activity, can be simple or dynamic. A dynamic indicator gives learners the option to filter their traces to refine their perception of the ongoing actions. In the case of Pco-Vision, learners can choose to see certain curves alongside the activity or individually. ${ }^{6}$ They can also refine their observations by zooming in on more or less short periods of time, which is a good way of "controlling" the traces. ${ }^{7}$ This paper presents a study conducted with approximately 50 students. It showed that, although such tools are appreciated, students mainly use them for judgement tasks and also for monitoring and planning actions. In order to implement these types of tasks, students preferred direct communication or used tangible tools (such as paper and blackboards).

The gStudy system, developed in the context of the learning kit project (Winne, Hadwin, $\&$ Gress, 2010), is a collaborative learning platform that offers different modes of communication and collaborative writing for distance learning. gStudy offers tools for the co-construction of concepts, such as creating notes, descriptive reports on the concepts of the course, concept cards, discussion tools and tools to express personal views concerning the concepts and resources that have been co-constructed.

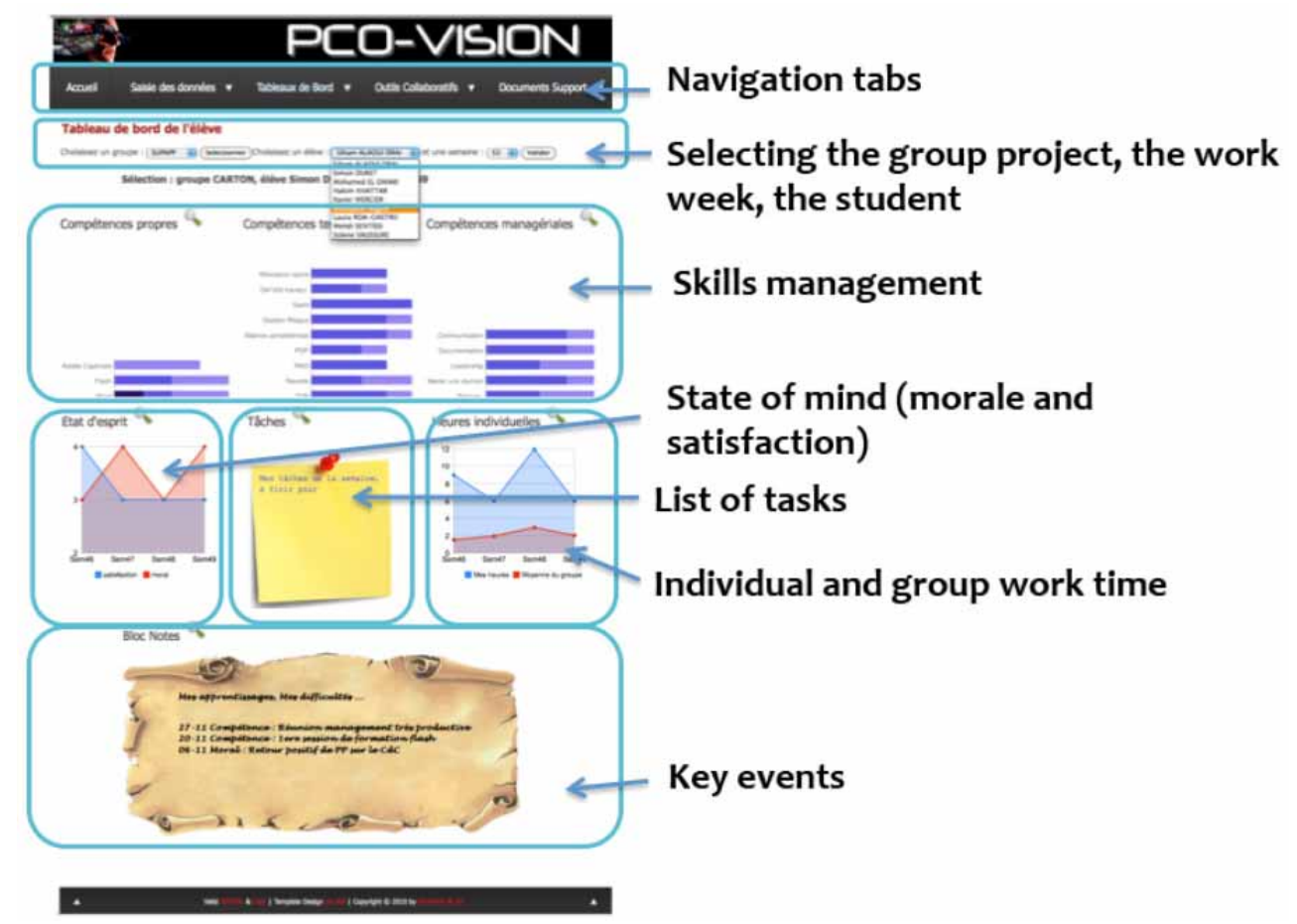

Figure 2. Individual Pco-Vision dashboard (Michel et al., 2012). 
gStudy was created to help students self-regulate when they participate in collaborative learning activities and to help groups conduct co-regulations, or regulate how their collaboration is organised by giving them the possibility, as a group, of rating the efficiency of the different collaborative strategies (Gress, Fior, Hadwin, \& Winne, 2010). ${ }^{8}$ For example, the gChat tool (in Figure 3) is used to stimulate collaboration in gStudy. Morris et al. (2010) used it to support and guide exchanges during the activity by attributing roles, presenting a script (general guidelines surrounding the organisation of the collaboration) and activating "prompts" (simulating the behaviour of a coach). ${ }^{9}$

These environments can be used before, during and after the learning activity, directly by the learners. However, indication systems which support regulation specifically at the end of the activity clearly dissociate the production activity sequences from the observation activities and the regulation activities. The regulation activities can give rise to formative or summative evaluations or to meetings where the activities and experiences are discussed, justified and explained. This is the case, for instance, in uses of an e-portfolio, which is a digital collection of a person's or a group's authentic and varied experiences during a certain period of time. ${ }^{10}$ The experiences are chosen and studied in order to be shared with other people, according to a specific rhetoric (Alexiou \& Paraskeva, 2010). ${ }^{11}$ A portfolio has two main functions in the context of a training session (Chang, 2008): Learning and evaluation. The learning portfolio is used to support reflection to make learners aware of their responsibility towards their own learning and to undergo regular self-evaluations. ${ }^{12}$ The evaluation portfolio is used at the end of the training period (or at specific moments in the training) for judgement by peers, teachers and internship supervisors. In this case, the portfolio is used as a product (result) of the learning process and the evaluation is made according to the experiences that are described and analysed.

\subsubsection{Coaching systems}

The aim of coaching systems is to give advice automatically. These systems can analyse the state of an individual or group activity and play a similar role to that of a teacher in order to

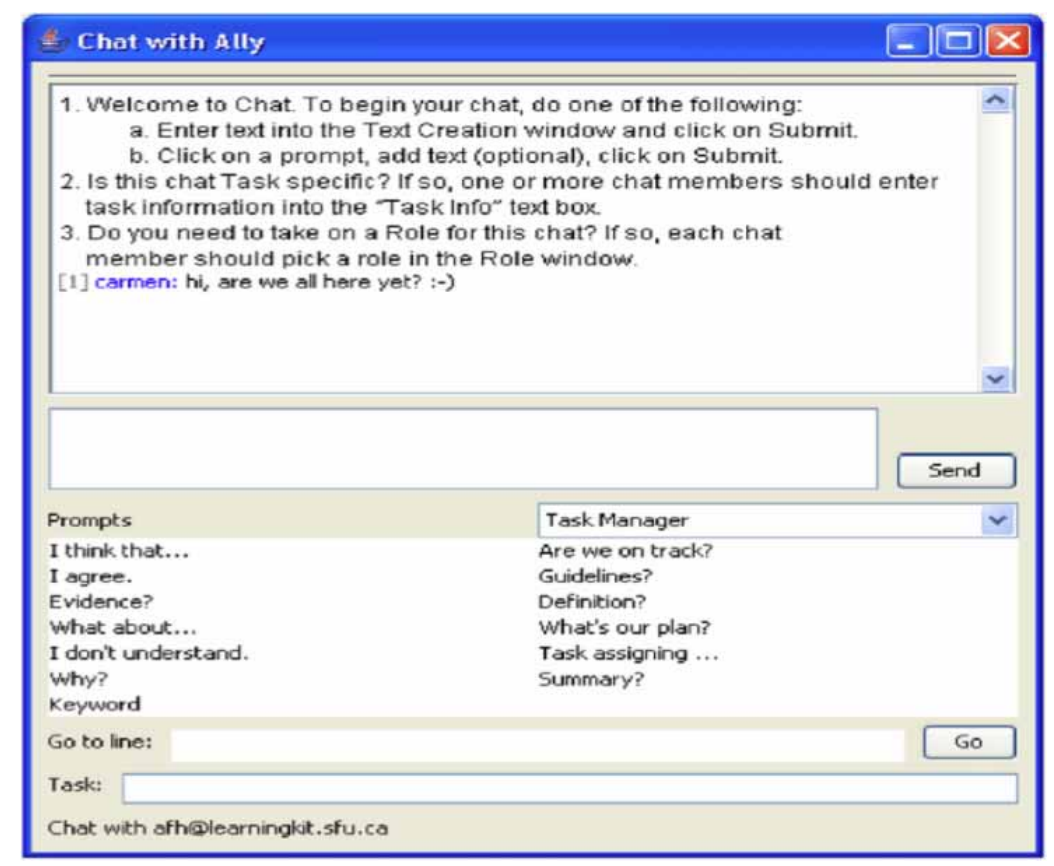

Figure 3. The gChat tool for the gStudy application. 
increase the efficiency of the learning process. These systems can, for the most part, be qualified as intelligent tutors.

MetaCTAT (Ramandalahy, Vidal, \& Broisin, 2010a) is attached to an existing intelligent tutor and helps students increase their metacognitive capacities. Although indication systems often have attributes for learning such as self-description, self-monitoring or search for help, few systems try to support processes linked to affects such as self-image, the act of assessing one's own learning or feelings of confidence. MetaCTAT takes part in the pedagogical activities of CTAT (Cognitive Tutoring Authoring Tools) by asking evaluation questions at the end of activity sequences. ${ }^{13}$ The questions concern targeted learning goals (multiple choice questions) and aim to assess effective learning and the learner's feelings. These feelings are considered according to three indicators: The feeling of learning with regard to each test question; the level of confidence related to the learning objectives that the learners think they have mastered; and the overall sense of achievement. ${ }^{14}$ The same researchers (Ramandalahy, Vidal, \& Broisin, 2010b) used the principles outlined in MetaCTAT in a similar application combined with training conducted with Moodle. The METAQUIZZ tool is based on the same pedagogical principles, as it asks for a confidence rating and a certainty rating ${ }^{15}$ (see the bubbles [2] and [4] in Figure 4) and has an immediate correction feedback feature in addition to the evaluation (see window [5] in Figure 4) as well as the possibility of consulting external information sources (links [6] and [7] in Figure 4).

The MI-EDNA system (Kumar, Gress, Hadwin, \& Winne, 2010) supports the previously presented gStudy system, providing additional assistance and advice during the activities. This system analyses the traces of a user in a learning situation. The collected traces are of varying types: Web browsing, note taking, chat, creating concept maps, etc. These traces are structured using an ontology in which all the interactions between the user and the application are represented. A second ontology contains information about the user's tactics and potential strategies. ${ }^{16}$ An inference engine links the facts (taken from an instance of the interaction trace ontology) with the rules (defined in the ontology of tactics and strategies). Recommendations can then be activated to help students in their learning strategy. ${ }^{17}$ For example:

- if a student only highlights a text, the system can recommend note taking;

- if a student only takes notes on a certain topic, the system can recommend other sources relating to the topic.

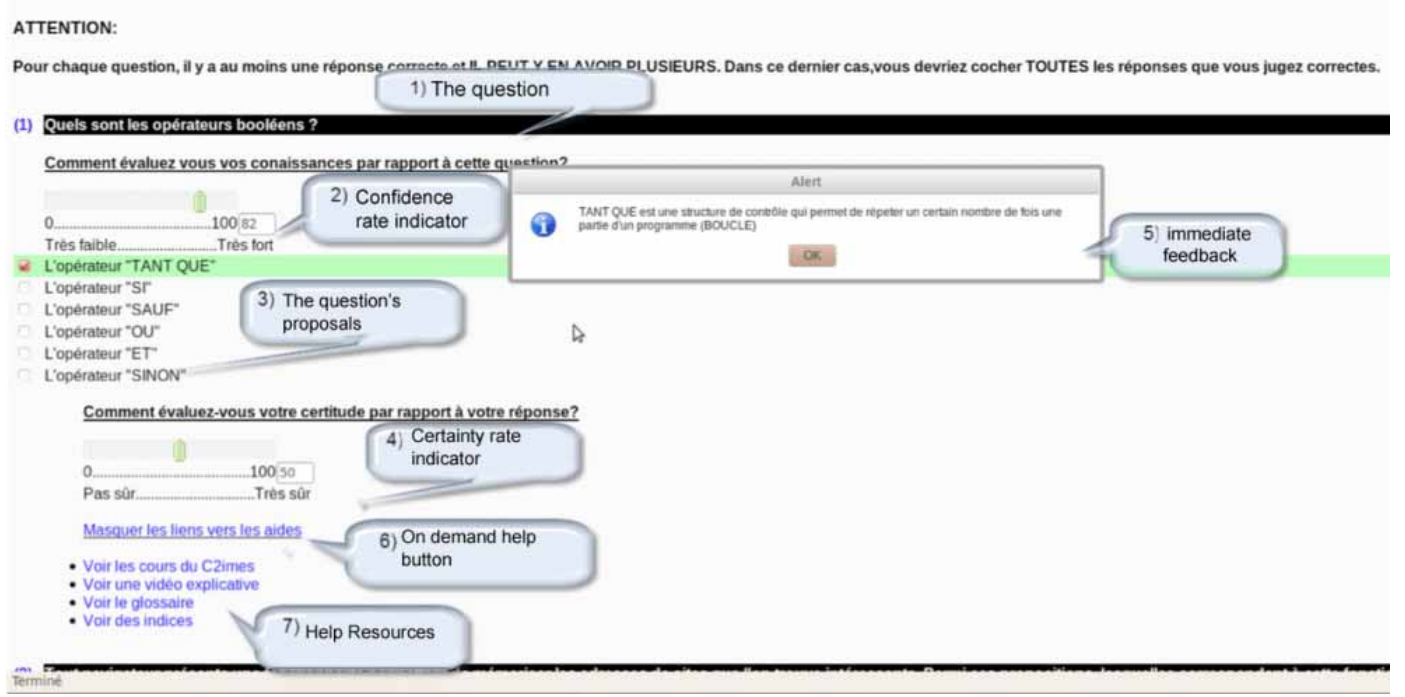

Figure 4. The METAQUIZZ interface (Ramandalahy et al., 2010b). 
One of the interesting aspects of this system lies in the fact that the assistance can be a mixed initiative. The system can automatically generate recommendations, but the learner can also take the initiative of asking for help. ${ }^{18}$ The simple action of asking for help and formulating a question already means that the learner takes a step back from the activity and adopts a reflexive position. This allows for more learner involvement in the learning process: therefore, "to enhance and to captivate the learners in the learning process it is quite appropriate to incorporate mixed-initiative interactive systems" (Shakya, 2005, p. 5). Moreover, in order to progress in the design of system interaction, researchers are intent on formalising the overall metacognitive process so that it can be integrated into an ITS, both as an inference rule and as an element that structures the activity. Peña et al. (2012) offer a model of the different elements that must be included to create an intelligent tutor to support metacognitive activity in education. The formalising and modelling steps have not yet been made operational. A few years of research are still needed to formalise inference rules and build mixed algorithms based on these models.

\subsection{Traces and reflexive processes in TEL}

To support reflexive processes for human learning, traces in computer environments can play two major roles (Coen, 2006). The first is the ability to "update the action" and it depends on the storage capacities ${ }^{19}$ of digital technologies. ${ }^{20}$ Such a process aims to make memories objective. Although the memories are reduced (the image is lost in an audio recording, the video is made according to a specific point of view, etc.), an outside person can have access to these records (in a teaching situation, for example). The second contribution made by digital technologies is its capacity to support the explanation of the action by giving the tools that the learner needs to process it. ${ }^{21}$ Indeed, calculation, statistical data, analysis or graphics can retrace the movement or evolution of a task, reveal the frequency of certain types of behaviour, etc. So digital technologies and traces lead to a special form of mediation, and give learners the opportunity to develop a reflexive point of view on their activity. The goal of the reflexive use of digital devices is therefore double: First, it allows learners to assert their individuality and enrich their skill sets; and secondly it provides resources in order to generate knowledge about the activity as it takes place in a complex and real situation.

The traces that are most often used to support active and co-constructive learning strategies are the results of activities produced individually or collectively. They can be intentionally produced by humans (such as in reports, discussion threads in forums, wikis, concept maps), or automatic records (number of times logged in, tasks done, tools used, etc.). ${ }^{22}$ Traces collected manually are used during or at the end of the activity to allow continuous regulation or support more complex types of reflexive observation (in the case of portfolios, for example). ${ }^{23}$ Traces collected automatically are linked to the management of individual and collective activities for a group of learners, specifically regarding awareness. ${ }^{24}$ Learners can then create controls during the activity. Yet traces that come from automatic recordings are not often used for this type of phenomenon. Others limits are linked with these types of TEL designs. They are presented in the next section.

\section{Limits of TEL using traces for reflexive purposes}

We notice that traces are mainly used to monitor and to measure the "amount" of activity that takes place and attempt to qualify it. Traces coupled with reflexivity can help promote deeper forms of learning rather than a stimulation of activity. But the use of traces for 
reflexive purpose is a complex task for humans. Moreover, reflexive practices can be organised for activities without TEL, for example in the case of face-to-face training or when training includes technology not proposed in TEL. This section develops these two points.

\subsection{Complexity for humans using traces}

Many obstacles stem from the fact that trace confrontation is not an obvious process and must systematically be sustained (which is mainly the tutor's role). Indeed, memory objectivation is made difficult by traces recording limited events; consequently, pairing possibilities between memory objectivation and the metacognitive strategies implemented by the subject are reduced (Hadwin, Oshige, Gress, \& Winne, 2007). Furthermore, TEL designers tend to think that learning traces taken from the recordings of interactions are easier to use because the subjects participated in the action. However, Gagnière (2010) showed the limits of a "free" confrontation with traces compared to a directed confrontation. ${ }^{25}$ Finally, a natural paradox exists between conceiving closely directed interactions - and, therefore, collecting traces according to predefined activity models - and implementing regulation activities using metacognition. Gagnière (2010) studied how the types of traces and interactions designed for TEL systems impacted the ways in which traces could later be potentially used. She noticed more specifically that a tool's potential to use traces to support metacognitive control actions depended on its ability to handle executive functions (i.e. monitoring and control functions used to analyse the consequences of actions and to make decisions). ${ }^{26} \mathrm{~A}$ few examples are given in Table 1.

The potential for traces to promote metacognitive regulation raises questions when the system becomes responsible for controlling and regulating instead of the learner. ${ }^{27}$ Traces (collected automatically or manually) are underused in TEL systems, although they could play a central role in mobilising the learner's reflexive process by, on one hand, objectifying the learner's activity, since traces are exterior to the object to which they refer and, on the other hand, putting semantics into the activity's proceedings, since traces produce signs jointly, as they are the result of a past action. Therefore, we believe that TEL systems as they allow traces to be collected and processed - have potential in two main areas: Describing the activity as closely as possible to the subject's lived experience ${ }^{28}$ and organising trace confrontations, allowing subjects to develop in their practise. ${ }^{29}$

\subsection{Traces and reflexive processes outside TEL}

We can note that most TEL systems support reflexive activity and regulation with traces during the activity. Indeed, most of time, mirroring, indication or coaching functions are implicit with learning activities so learners do not regulate themselves with TEL environments after the end of the learning period. Moreover, learners can be engaged with various learning process or TEL environments to build complex skills but must use only one reflexive tool. If a reflexive tool is included in the TEL environment it is not possible to use the same reflexive tool for complex skills. This is why researchers are working on systems that can analyse traces and present indicators outside predefined TEL systems. We present some examples in the following section.

Some researchers are working on dynamic tools where functions of mirroring and incitation are not predefined for a specific learning activity. The main goal consists in letting teachers, tutors and also students use them with different learning tools. In order to give users the opportunity to "play" with their traces, ${ }^{30}$ and go beyond the specific management 
Table 1. Analysing tracing tools according to their metacognitive regulation capacities (Gagnière, 2010, p. 120).

\begin{tabular}{|c|c|c|c|c|}
\hline Trace tools & $\begin{array}{l}\text { Extent to which the } \\
\text { executive function } \\
\text { takes charge } \\
\text { (associated to the } \\
\text { types of } \\
\text { environments) }\end{array}$ & Types of traces & $\begin{array}{l}\text { Amount of } \\
\text { metacognitive } \\
\text { activities } \\
\text { required }\end{array}$ & $\begin{array}{c}\text { Amount of } \\
\text { traces/ } \\
\text { metacognition } \\
\text { accounting }\end{array}$ \\
\hline $\begin{array}{l}\text { SQL tutor skills } \\
\text { indicator } \\
\text { (Mitrovic \& } \\
\text { Martin, } \\
\text { 2002) }\end{array}$ & Very high; ITS & $\begin{array}{l}\text { Learning report per } \\
\text { knowledge unit }\end{array}$ & $\begin{array}{l}\text { Very low; the } \\
\text { learner is } \\
\text { exempt from } \\
\text { an executive } \\
\text { role }\end{array}$ & Low \\
\hline $\begin{array}{l}\text { OLMets skills } \\
\text { indicator } \\
\text { (Bull \& Kay, } \\
\text { 2008) }\end{array}$ & $\begin{array}{l}\text { Very high; digital } \\
\text { environments }\end{array}$ & $\begin{array}{l}\text { Formative } \\
\text { assessment } \\
\text { (accurate } \\
\text { knowledge, } \\
\text { misconception of } \\
\text { a concept) }\end{array}$ & & \\
\hline $\begin{array}{l}\text { StudyDesk } \\
\text { progress } \\
\text { report } \\
\text { (Narciss, } \\
\text { Proske, \& } \\
\text { Koerndle, } \\
\text { 2007) }\end{array}$ & & $\begin{array}{l}\text { Tasks completed } \\
\text { accurately }\end{array}$ & & \\
\hline $\begin{array}{l}\text { Information } \\
\text { search } \\
\text { graphs (Saito } \\
\text { \& Miwa, } \\
\text { 2007) }\end{array}$ & $\begin{array}{l}\text { High; meta } \\
\text { programmes }\end{array}$ & $\begin{array}{l}\text { Information search } \\
\text { that is represented } \\
\text { graphically }\end{array}$ & $\begin{array}{l}\text { Medium; some } \\
\text { decision- } \\
\text { making by the } \\
\text { learner }\end{array}$ & Medium \\
\hline $\begin{array}{l}\text { DARN tool } \\
\text { (Schauble, } \\
\text { Raghavan, \& } \\
\text { Glaser, } \\
\text { 1993) }\end{array}$ & $\begin{array}{l}\text { Low; cognitive } \\
\text { simulation tool }\end{array}$ & $\begin{array}{l}\text { Sequence of } \\
\text { activities that } \\
\text { represent the } \\
\text { evolution of the } \\
\text { intellectual } \\
\text { partnership with } \\
\text { the cognitive tool }\end{array}$ & High & High \\
\hline $\begin{array}{l}\text { Natural traces; } \\
\text { succession of } \\
\text { design } \\
\text { sketches }\end{array}$ & $\begin{array}{l}\text { Very low; author } \\
\text { tool }\end{array}$ & $\begin{array}{l}\text { Externalisation of } \\
\text { the design process }\end{array}$ & Very high & High \\
\hline
\end{tabular}

of traces for each TEL system, research questions concern the architecture of TBS and the design of human-computer interfaces (HCI).

Concerning TBS' architecture, an issue concerns the fact that a TEL system is rarely used on its own and in an exclusive way. Learners often use other computerised tools simultaneously (to communicate, to find resources, etc.). The study of traces must be revisited to include these user patterns. Researchers then need to focus on defining methods and solutions to manage traces more accurately and promote system interoperability. Traces have indeed become objects of study. As a generic definition, a trace can be considered as a collection of observed elements (obsels), situated in time, an obsel being any structured information that stems from the observation of an interaction (Settouti, Prié, Marty, \& Mille, 
2009). Butoianu, Vidal, and Broisin (2012) chose to work on a generic trace model that made it possible to structure and add semantics to the observed data. One of the specificities of this research was proposing a distributed architecture which made the sharing and reusing of traces that had been collected by different and heterogeneous IT environments (TEL systems and others) easier. ${ }^{31}$ A way of implementing this research has been recently proposed (Butoianu et al., 2012), using the standardised definitions for information related to system management, applications and services, specifically using the common information model (CIM). The information taken from heterogeneous tools is represented in a unified and expandable structure. In order to observe a new application, two steps need to be taken. The first step consists of describing the application, its resources and activities in the CIM. The second step consists of integrating an agent in the targeted application in order to recover the traces and communicate them to a trace management system.

Concerning HCI, the researchers of the previously presented Pco-vision project are working on a system where students can build their own indicators to support self-regulation (Ji, Michel, Lavoué, \& George, 2013). Building the indicator consists of defining the process of calculation and then the visualisation modes. The proposed architecture combines activity traces (which are recorded automatically by the system) and reporting traces (which are reported by learners themselves). ${ }^{32}$ The process is currently operational for specialists but is not accessible to simple users. Researchers are working on usable HCI to allow users to carry out the process by themselves. ${ }^{33}$

Some researchers are also working on identifying models to support trace analyses for a large category of systems used in a learning context. For example, Li, Abel, and Barthès (2014) are working on methods of tracing collaborative web systems (CWS). At this stage, their contribution is not complete TBS but they propose a model for tracing collaboration and complex filters to analyse individual and collective traces produced when CWS are used. ${ }^{34}$ They apply their results in two contexts: For strengths, weaknesses, opportunities, and threats analysis of a given collaboration situation and for organisational learning observation (more precisely knowledge capitalisation through collaboration).

Mathern, Mille, Cordier, Cram, and Zarka (2012) studied the general structure and features of TBS for interactive knowledge discovery. These researchers claim that interactivity is the key issue to help the end-user to discover knowledge from traces. The key criteria for TBS' HCI are integration, iteration and interactivity, representing, respectively a unique way of interacting at a knowledge level, giving the user the opportunity of interacting with the system at any phase of the discovery process and knowledge sharing between users and systems through appropriate representations and models. ${ }^{35}$ Another key concept is actionability, that is, the discovery of "automata" as the signatures of behaviours and their use for knowledge discovery purposes. ${ }^{36}$ Several challenges of knowledge discovery remain unsolved when using TBS on a large scale. ${ }^{37}$

\section{Theory-enhanced learning system requirements for smart uses of traces}

\subsection{Summary of the reflexive uses of traces with TEL}

We have presented many frameworks where the reflexive use of trace is useful in supporting the learning process with a TEL system. We have seen that the educative potential of mirroring tools is still underused. Mirroring systems are often reserved for helping researchers to understand and analyse instrumented learning situations or to help teachers to monitor and evaluate learners. A limited number of systems offer these tools to learners. This can 
be explained by the fact that providing information to learners about the activity or their behaviour is not always enough to foster metacognitive analysis.

Indication systems are the most widely used reflexive systems. Indeed, during the activity or at the end of the activity, they provide the user with a synthetic and usable visualisation of traces in a specific area of the interface. They are offered inside or outside TEL systems. In some cases, they enable the user to use the traces and define the type of regulation activity. In others cases they give the user the opportunity to wholly adapt the reflexive process. However, at this stage, the research propositions are not mature. Indeed, models and processes for trace collection, transformation and visualisation are mostly closely linked to a specific context or a type of system. Large amounts of work are being undertaken in order to design usable HCI and to understand the human preferences and limits during traces manipulation. Other work is seeking to propose application programming interfaces (API) in order to make TBS' processes accessible from TEL systems.

Coaching systems play an active, reflexive role since they create diagnostics and propose remediation. We do not believe that an active role of the computer necessarily implies that learners become more passive. It mainly depends on how recommendations are given. If the recommendations are too prescriptive, there is a risk of making learners reliant on the system, as the computer application replaces the learner when conducting thought-based tasks. By contrast, if instructions are too vague, learners can not integrate them into their activities. The challenge lies in finding the right level of recommendations to foster reflexive learning. Systems designed around the idea of a human-machine partnership seem to be the most adapted to involve learners. Finally, systems in which the decisions taken by the system are visible can encourage learners to distance themselves from the activity and learning. This idea is not easy to implement since a way must be found to make the system behaviour understandable (inference rules, for example) for humans.

Frameworks have also been presented to illustrate how TBS can be used outside TEL systems for reflexive learning purposes. The goal of these kinds of TBS is to propose integration, iteration, interactivity and actionability in regard to trace models, trace collection, trace manipulation and trace representation. In order to support knowledge discovery, models must evolve dynamically. Some tools exist at this stage of research but they are dedicated to specific learning contexts. Indeed, there are no operational TBS corresponding to all target specifications. Researchers are working on models or processes in order to design tools that are not only multi-purpose and dynamic tools, but also able to handle a large volume of data. These problems have not been solved and many research challenges remain.

\subsection{Condition for reflexive smart uses of traces for Learning}

As explained above, there are a lot of TEL systems which support reflexivity in learning by using traces. Our review allowed us to find important properties of these systems to scaffold reflexivity and support learning. Some requirements have thus emerged from this review. Our analysis of their limits enabled the completion of the following requirements. In this section we summarise the eight requirements we consider fundamental for smart uses of traces in TEL systems, presented in Table 2.

In order for the reflexive TEL(T) systems to be able support these requirements, we recommend organising design around three key processes. These are presented in the next section. 
Table 2. Requirements for TEL systems aspiring to a smart use of traces.

\begin{tabular}{ll}
\hline Requirement \#1 & $\begin{array}{c}\text { Record as many human-computer interactions as possible } \\
\text { Requirement \#2 } \\
\text { Requirement \#3 }\end{array}$ \\
$\begin{array}{l}\text { Have large storage capacity } \\
\text { Provide a usable visualisation of traces in a specific area of the interface } \\
\text { (to instantiate the externality of the object to which they refer) } \\
\text { Requirement \#4 }\end{array}$ & $\begin{array}{l}\text { Indicate which learners are involved in the traced activity } \\
\text { Propose recording traces automatically or manually. The two recording } \\
\text { methods can be combined. In the case of an automatic recording, } \\
\text { this must be disengageable } \\
\text { Offer "documented" confrontation with traces, to facilitate this process } \\
\text { Requirement \#6 }\end{array}$ \\
Requirement \#7 & $\begin{array}{l}\text { Provide the learner with opportunities for action on traces, for example, } \\
\text { visualising traces, editing them and even creating indicators } \\
\text { Propose control over the traces and regulation of the activities that are } \\
\text { the responsibility of the learner }\end{array}$ \\
\hline
\end{tabular}

\subsection{Processes of reflexive TEL(T) systems}

According to us, reflexive TEL(T) systems must be based on three key processes represented in Figure 5 below:

- The gathering ([b] in Figure 5) of interaction elements (a), which will later become traces: These elements include actions carried out by the learners (free or prescribed by educational scenarios) and feedback given by the system. Collection is made according to a collection model built a priori (before the interactions have taken place). This model is very important because it determines the content of traces. The capacity to record human-system interactions is its only limit. This collection can be made in an "automatic" or "mixed" way. An "automatic" collection means that the machine records the interactions based on the collection model. This type of collection presents the advantage of having high storage and recording capacities, and it can also be reproduced to a certain extent. It is however limited when it comes to faithfully describing the user's activity, since it only renders a part of the interactions. In addition to the automatic recording of interactions, a "mixed" collection gives the user the opportunity to express an opinion concerning the interactions with opinion polls, appraising one's position on a scale, confirming or not confirming calculations made by the system, etc. With such a collection, the user's point of view can be integrated in order to "qualify" the activity. This type of collection presents limitations in the treatment of what is collected by the system, especially regarding open verbal information.

- The transformation (c) of gathered recordings: These consist of two types of transformations. First, transformations such as "machine calculations" in which recordings are used to "extract" the information according to a specific intent. This may be filtering, searching for interaction motives, calculating indicators and comparisons with reference values, etc. Second, "presentation" transformations make it possible for users to access recordings, meaning that the users are presented with the recordings in the interface. This type of transformation can take place on recordings that have not been transformed or on recordings transformed by calculations. Transformation processes and transformed traces are stored in TBS (Settouti et al., 2009). Both types can be produced or merely accessed (d2) by the TEL system according to the need expressed in the pedagogical intent.

- Possible action on and outside the learning environment: Traces can be used with a predefined pedagogical intent $(\mathrm{d} 2)$. In this context, actions suggested to the user 


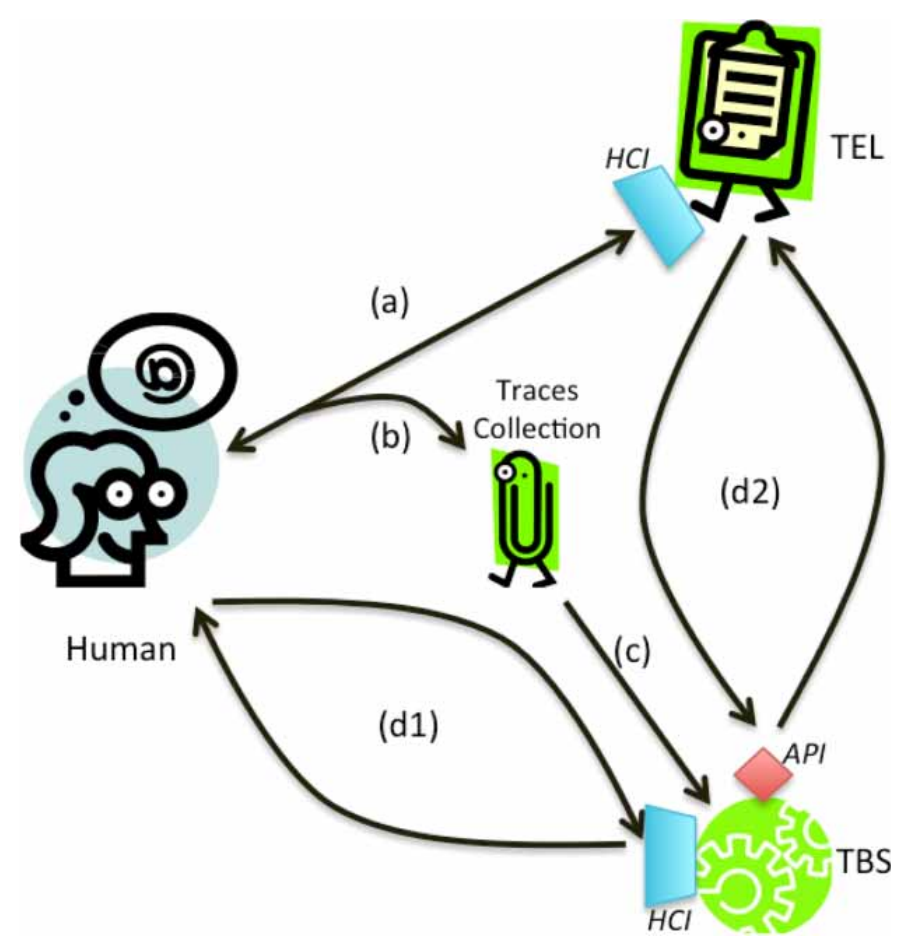

Figure 5. Synthesis of the processes that a reflexive TEL(T) system must include.

either use data from traces, or, through the TEL system, suggest other actions that the user can conduct on the traces (these types of actions are not specifically identified in the figure; they are part of the human-TEL interactions [a]). Actions on traces can occur, such as editing, deleting, sharing, etc. (these are actions initiated by the learner) or certain types of feedback using traces (these are actions done by the system). The learner can therefore use traces without a predefined pedagogical intent (d1) allowing the initiation of treatments of traces according to one's own objectives. The user accesses the TEL and TBS through HCI, whereas TEL systems communicate with TBS using API.

A learner's interactions with the TEL(T) system are therefore defined by actions on traces or feedback using traces, as well as "autonomous actions" towards the TEL system as a whole.

\section{Discussion and conclusion}

In this article, we have shown that traces in TEL systems are used in many different ways. We have adopted a social constructivist view of human learning, in which reflexive activities are central, since they allow learners to distance themselves from their activity, to "make it an object." This distancing effect leads to personal development. In this article, we outlined how reflexive processes are implemented at different human levels (intra- or intersubject), learning levels (from mirroring to guiding; Jermann, Soller, \& Lesgold, 2004) and at different times (during or after the activity). Indeed, the different situations and TEL systems presented show that reflexive activities are supported in varying ways. With mirroring systems or indication systems, learners are given plenty of leeway to develop the distancing process stemming from the presentation of traces. With coaching systems the activity is structured. Learners are guided to be more aware and to judge how they react and think. But we have shown that if a system's advice interactions are 
predefined, there is a risk of overly controlling the learner's activity, thus preventing the learner from triggering reflexive processes. This study drew up the potential and limits of reflexive systems based on traces. We then highlighted the characteristics that TEL systems should have to foster reflexivity. They are summarised in eight requirements and three key processes needed for the design.

We have noticed that a paradox can occur in situations that are explicitly designed to support reflexivity: In order to have reflexivity, the learner - not the system - must be in charge of controlling and regulating the activity. We therefore understand the importance of the notion of the "locus of metacognitive processing" developed by Jermann et al. (2004, p. 266):

Research in distributed cognition suggests that cognitive and metacognitive processes might be spread out and shared among actors in a system.... The locus of processing describes the location at which decisions are made about the quality of the student interaction, and how to facilitate this interaction. ... Systems that collect interaction data and construct visualizations of this data tend to place the locus of processing at the user level, whereas systems that advise and coach aggregate and process this information directly.

At the same time, reflexive processes in learning are not "standard" interactional processes: We are aware that leading a learning process is a costly endeavour which often goes against existing methods (Pastré, 2006) and which must be supported (by a teacher and/or by a TEL system). A TEL system can contribute to enriching the self-confrontation process with traces, in comparison with a "free" self-confrontation (i.e. not assisted), which can be without effect on the learner's development. Contrary to guiding systems, mirroring systems reflect the interaction traces back to the learners without placing these traces in relation to indicators. In these systems, the learner has the responsibility to embrace the traces that have not been interpreted by the system. Finally, whether the TEL(T) is a mirroring system, an indication or a guiding system, learners can develop their reflexive capacities as long as they can take ownership of the interaction traces presented.

When thinking about the reflexive use of traces in TEL systems as a form of assistance to the act of learning, the aim is to reach "emancipatory reflexivity" (Gapenne, 2006), carrying the cognitive information needed in order, eventually, to forego assistance. Most designers aim to reach this degree of reflexivity by working on self-regulated forms of learning, using traces (Azevedo, 2007; Hadwin et al., 2007). In order to reach "emancipatory reflexivity" researchers have to work on three different levels.

At the design level, questions remain concerning the support of self-regulation (Peña et al., 2012; Schraw, 2007; Tanes, Arnold, King, \& Remnet, 2011; Veenman, 2007). Research must be conducted on the design visual and interactional affordances (Gibson, 1979) for the use of traces (Gapenne, 2006). Indeed, transformations like selection, filtering, cutting, etc., are essential for learners to manipulate traces in order to grasp them: By editing, sharing, annotating and so forth. Research must also be carried out on the gathering process. It is the first enhancement process of a TEL system with traces and conditions the basis of collection in which all the other processes take place. Concerning the structuration of traces, most systems use an a priori collection model that only gives a patchy reconstitution of past experience. Dynamic collection models could be designed to let the user or the system adapt to real needs, uses and habits. Manual recording usually done by using prompts or forms can also be studied in order to propose finer techniques such as "thinkaloud" (Bannert \& Mengelkamp, 2008; Veenman, 2007).

At the individual and micro-social levels, implementing TEL(T) systems for learning will foster the development of trace use. But using traces must be learnt since the 
process is not self-evident. Research must first be carried out to help users understand the usefulness of traces for reflexive purposes. Guides on the reflexive uses of a TEL system can simply help the users to discover its possible uses. Various results have to be found on this subject, especially concerning the methods to evaluate reflexive learning with TEL(T) systems. After, it will then be interesting to observe how transfers in the use of traces will occur, for example, how teachers will choose to implement traces in the context of learning situations without TEL or how learners, aware of these practices, will use traces in their learning strategies for life-long learning, that is to say situations in which learning is not the aim of the ongoing activity (Pastré, 2006).

Thirdly, at the societal level, massively developing TEL(T) systems and other devices that use traces will contribute to creating new digital cultures. These cultures will build and condition not only the practices but also the values delimited by these objects. It is therefore necessary to understand these phenomena and to create training sessions to raise awareness regarding these practices. This is essential in order to avoid new forms of digital divide.

In this conclusion, we have focused more specifically on research questions linked to the effective design of TEL(T) systems or pedagogical situations that use them. The questions relative to the transfer of uses, digital cultures and the spread of these types of devices in society are not limited to TEL systems but also concern other systems based on traces.

\section{Disclosure statement}

No potential conflict of interest was reported by the authors.

\section{Notes}

1. In Section 4.2 we present eight requirements for reflexive smart uses of traces for learning. This observation illustrates requirements \#3 (usable visualisation of traces) and \#4 (learners' involvement) from Table 2.

2. This observation illustrates requirement \#8 (learners' responsibility) from Table 2 in Section 4.2.

3. This observation illustrates requirement \#7 (action on traces) from Table 2 in Section 4.2.

4. This observation illustrates requirements \#4 and \#6 (documented confrontation of traces) from Table 2 in Section 4.2.

5. This observation illustrates requirement \#5 (automatic and manual recording) from Table 2 in Section 4.2 .

6. This observation illustrates requirement \#4 from Table 2 in Section 4.2.

7. This observation illustrates requirement \#7 from Table 2 in Section 4.2.

8. This observation illustrates requirement \#4 from Table 2 in Section 4.2.

9. This observation illustrates requirement \#8 from Table 2 in Section 4.2.

10. This observation illustrates requirement \#4 from Table 2 in Section 4.2.

11. This observation illustrates requirements \#3 and \#5 from Table 2 in Section 4.2.

12. This observation illustrates requirement \#8 from Table 2 in Section 4.2.

13. This observation illustrates requirement \#5 from Table 2 in Section 4.2.

14. This observation illustrates requirement \#8 from Table 2 in Section 4.2.

15. This observation illustrates requirements $\# 5$ and \#6 from Table 2 in Section 4.2.

16. This observation illustrates requirement \#5 from Table 2 in Section 4.2.

17. This observation illustrates requirement \#7 from Table 2 in Section 4.2.

18. This observation illustrates requirement \#8 from Table 2 in Section 4.2.

19. This observation illustrates requirement \#7 from Table 2 in Section 4.2.

20. This observation illustrates requirements \#1 (exhaustive recording) and \#2 (large storage capacities) from Table 2 in Section 4.2.

21. This observation illustrates requirements \#3, \#6 and \#7 from Table 2 in Section 4.2.

22. This observation illustrates requirement \#5 from Table 2 in Section 4.2. 
23. This observation illustrates requirement \#8 from Table 2 in Section 4.2.

24. This observation illustrates requirements \#3 and \#4 from Table 2 in Section 4.2.

25. This observation illustrates requirement \#6 from Table 2 in Section 4.2.

26. This observation illustrates requirements \#3, \#6 and \#7 from Table 2 in Section 4.2.

27. This observation illustrates requirement \#8 from Table 2 in Section 4.2.

28. This observation illustrates requirements \#1, \#2, \#4 and \#5 from Table 2 in Section 4.2.

29. This observation illustrates requirements \#3, \#6, \#7 and \#8 from Table 2 in Section 4.2.

30. This observation illustrates requirements \#3, \#6, \#7 and \#8 from Table 2 in Section 4.2.

31. This observation illustrates requirements $\# 1$ and $\# 2$ from Table 2 in Section 4.2.

32. This observation illustrates requirement \#5 from Table 2 in Section 4.2.

33. This observation illustrates requirements \#7 and \#8 from Table 2 in Section 4.2.

34. This observation illustrates requirements \#1 and \#4 from Table 2 in Section 4.2.

35. This observation illustrates requirements \#1 and \#3 from Table 2 in Section 4.2.

36. This observation illustrates requirements \#6, \#7 and \#8 from Table 2 in Section 4.2.

37. This observation illustrates requirement \#2 from Table 2 in Section 4.2.

\section{Notes on contributors}

Sébastien George is Full Professor in the Department of Computer Science, Institute of Technology of the University of Maine, Laval. He is a member of the LIUM Research Laboratory. He received his Ph.D. from the University of Maine in 2001. There he designed and developed an environment dedicated to distant project-based learning. Then he did a postdoctoral fellowship at the TeleUniversity of Quebec in Canada. He was Associate Professor at INSA Lyon from 2002 to 2013. In 2010, he qualified as HDR, an accreditation to supervise Ph.D. students. His major fields of interest are computersupported collaborative learning, human-computer interactions, computer-mediated communication, assistance to human tutoring in distance education and serious gaming.

Christine Michel is Associate Professor in the Department of Industrial Engineering, INSA Lyon. She is a member of the LIRIS Research Laboratory. She received her Ph.D. from the University Claude Bernard Lyon 1 in France in 1999. She worked on information structuration and personalisation in cases of information retrieval (IR) processes and designed a protocol to evaluate personalised IR systems. In 1999 she joined the University of Bordeaux III to work on informational systems' evaluation and the analysis of their uses in the contexts of academic learning using log traces. In 2003 she joined INSA Lyon and focused her work on individual and collaborative learning process observation and the design of technology-enhanced learning systems using traces of activity for reflexive practice.

Magali OllagnierBeldame is a CNRS researcher. She is a member of the ICAR Research Laboratory. She holds a Ph.D. in cognitive science from the Lyon 2 University, obtained in 2006. Using an empirical approach, she studies interactional processes occurring in computersupported collaborative work situations. She is especially interested in the appropriation of digital tools and trace-based reflexive activities.

\section{ORCID}

Sébastien George (D) http://orcid.org/0000-0003-0812-0712

\section{References}

Alexiou, A., \& Paraskeva, F. (2010). Enhancing self-regulated learning skills through the implementation of an e-portfolio tool. Procedia - Social and Behavioral Sciences, 2, 3048-3054.

Azevedo, R. (2007). Understanding the complex nature of self-regulatory processes in learning with computer-based learning environments: An introduction. Metacognition and Learning, 2(2-3), 57-65.

Bannert, M., \& Mengelkamp, C. (2008). Assessment of metacognitive skills by means of instruction to think aloud and reflect when prompted: Does the verbalisation method affect learning? Metacognition and Learning, 3(1), 39-58. 
Bonwell, C., \& Eison, J. (1991). Active learning: Creating excitement in the classroom (ASHE-ERIC Higher Education Report No. 1). Washington, DC: George Washington University.

Bull, S., \& Kay, J. (2008). Metacognition and open learner models. In I. Roll \& V. Aleven (Eds.), Proceedings of workshop on metacognition and self-regulated learning in educational technologies, (pp. 7-20). International Conference on Intelligent Tutoring Systems, Montreal, Canada.

Butoianu, V., Vidal, P. \& Broisin, J. (2012). A model-driven approach to actively manage TEL indicators. In T. Amiel \& B. Wilson (Eds.), Educational multimedia, hypermedia \& telecommunications conference (EDMEDIA 2012) (pp. 1757-1765). Advancement of Computing in Education (AACE): Denver.

Chan, T. W., Roschelle, J., Hsi, S., Kinshuk, K., Sharples, M., Brown, T., ... Hoppe, U. (2006). Oneto-one technology-enhanced learning: An opportunity for global research collaboration. Research and Practice in Technology Enhanced Learning, 1(1), 3-29.

Chang, C. C. (2008). Enhancing self-perceived effects using web-based portfolio assessment. Computers in Human Behavior, 24(4), 1753-1771.

Coen, P. F. (2006). Les technologies: des aides précieuses pour développer la réflexivité des apprenants. Revue des hautes écoles pédagogiques et institutions assimilées de Suisse romande et $d u$ Tessin, 3(1), 123-131.

Cortez, C., Nussbaum, M., Woywood, G., \& Aravena, R. (2009). Learning to collaborate by collaborating: A face-to-face collaborative activity for measuring and learning basics about teamwork. Journal of Computer Assisted Learning, 25(2), 126-142.

Gagnière, L. (2010). Comment inciter les régulations métacognitives pour favoriser la résolution de problèmes mal structurés? (Doctoral dissertation). University of Geneeva, Geneva.

Gapenne, O. (2006). Introduction: Relation d'aide et transformation cognitive. Intellectica, 44(2), 7-16.

Gibson, J. J. (1979). The ecological approach to visual perception. Boston, MA: Houghton Mifflin.

Gress, C. L. Z., Fior, M., Hadwin, A. F., \& Winne, P. H. (2010). Measurement and assessment in computer-supported collaborative learning. Computers in Human Behavior, 26(5), 806-814.

Hadwin, A. F., Oshige, M., Gress, C. L. Z., \& Winne, P. H. (2007). Examining trace data to explore self-regulated learning. Metacognition and Learning, 2(2-3), 107-124.

Jermann, P., \& Dillenbourg, P. (2008). Group mirrors to support interaction regulation in collaborative problem solving. Computers \& Education, 51(1), 279-296.

Jermann, P., Soller, A., \& Lesgold, A. (2004). Computer software support for CSCL. In J. W. Strijbos, P. A. Kirschner \& R. L. Martens (Eds.), What we know about CSCL, Computer-Supported Collaborative Learning Series (Vol. 3, pp. 141-166). Dordrecht: Kluwer Academic.

Ji, M., Michel, C., Lavoué, E., George, S. (2013). An architecture to combine activity traces and reporting traces to support self-regulation processes. In IEEE Computer Society (Ed.), Proceedings of the 13th IEEE international conference on advanced learning technologies (pp. 87-91). IEEE Computer Society: Beijing.

Kolb, D. A. (1984). Experiential learning: Experience as the source of learning and development. Englewood Cliffs, NJ: Prentice-Hall.

Kumar, V. S., Gress, C. L. Z., Hadwin, A. F., \& Winne, P. H. (2010). Assessing process in CSCL: An ontological approach. Computers in Human Behavior, 26(5), 825-834.

Li, Q., Abel, M. H., \& Barthès, J. P. A. (2014). Modeling and exploiting collaborative traces in webbased collaborative working environment. Computers in Human Behavior, 30(1), 396-408.

Mathern, B., Mille, A., Cordier, A., Cram, D., \& Zarka, R. (2012). Towards a knowledge-intensive and interactive knowledge discovery cycle. In Proceedings of the 20th ICCBR Workshop (pp. 151-162). Lyon, France.

Michel, C., Lavoué, E., \& Piétrac, L. (2012). A dashboard to regulate project-based learning. Proceedings of the 7th European conference on technology enhanced learning (pp. 250-263). Saarbrücken: Springer.

Mitrovic, A., \& Martin, B. (2002). Evaluating the effects of open student models on learning. Paper presented at the adaptive hypermedia and adaptive web-based systems: Second International Conference, AH 2002, Malaga, Spain.

Morris, R., Hadwin, A. F., Gress, C. L. Z., Miller, M., Fior, M., Church, H., \& Winne, P. H. (2010). Designing roles, scripts, and prompts to support CSCL in Study. Computers in Human Behavior, 26(5), 815-824.

Narciss, S., Proske, A., \& Koerndle, H. (2007). Promoting self-regulated learning in web based learning environments. Computers in Human Behavior, 23(3), 1126-1144. 
Pastré, P. (2006). Apprendre à faire. In E. Bourgeois \& G. Chapelle (Eds.), Apprendre et faire apprendre (pp. 109-121). Paris: PUF.

Peña, A., Kayashima, M., \& Dominguez, R. (2012). A conceptual model of metacognition to shape knowledge and regulation. Proceedings of the the 11th International ITS Conference 2012 Workshops (p. 4). Chania.

Ramandalahy, T., Vidal, P., \& Broisin, J. (2010a). An intelligent tutoring system supporting metacognition and sharing learners' experiences. In V. Aleven, J. Kay, \& J. Mostow (Eds.), Intelligent tutoring systems: Lecture notes in computer science (pp. 402-404). Berlin: Springer.

Ramandalahy, T., Vidal, P., \& Broisin, J. (2010b). Conception d'un tuteur intelligent : le cas du questionnaire. In TICE2010-7ème Colloque Technologies de l'Information et de la Communication pour l'Enseignement. Nancy, France.

Reusser, K. (2001). Co-constructivism in educational theory and practice. In N. J. Smelser \& P. B. Baltes (Eds.), International encyclopedia of the social \& behavioral sciences (pp. 2058-2062). Oxford: Elsevier Science.

Saito, H., \& Miwa, K. (2007). Construction of a learning environment supporting learners' reflection: A case of information seeking on the web. Computers \& Education, 49(2), 214-229.

Schauble, L., Raghavan, K., \& Glaser, R. (1993). The discovery and reflection notation: A graphical trace for supporting self regulation in computer-based laboratories. In S. LaJoie \& S. Derry (Eds.), Computers as cognitive tools (pp. 319-337). Hillsdale, NJ: Lawrence Erlbaum Associates.

Schön, D. A. (1987). Educating the reflective practitioner: Towards a new design for teaching and learning in the professions. New York, NY: The Free Press.

Schraw, G. (2007). The use of computer-based environments for understanding and improving selfregulation. Metacognition and Learning, 2(2), 169-176.

Settouti, L. S., Prié, Y., Marty, J. C., \& Mille, A. (2009). A trace-based system for technologyenhanced learning systems personalisation. In Proceedings of the 9th IEEE international conference on advanced learning technologies (pp. 93-97). Riga, Latvia.

Shakya, J. (2005). Knowledge engineering and knowledge dissemination in a mixed-initiative ontological framework (Doctoral dissertation). School of Interactive Arts and Technology, Simon Fraser University.

Soller, A., Martinez, A., Jermann, P., \& Muehlenbrock, M. (2005). From mirroring to guiding: A review of state of the art technology for supporting collaborative learning. International Journal of Artificial Intelligence in Education, 15(4), 261-290.

Tanes, Z., Arnold, K. E., King, A. S., \& Remnet, M. A. (2011). Using signals for appropriate feedback: Perceptions and practices. Computers \& Education, 57(4), 2414-2422.

Treude, C., \& Storey, M. A. (2010). Awareness 2.0: Staying aware of projects, developers and tasks using dashboards and feeds. In Proceedings of the 32nd ACM/IEEE International Conference on Software Engineering (Vol. 1, pp. 365-374). New York, NY.

Veenman, M. (2007). The assessment and instruction of self-regulation in computer-based environments: A discussion. Metacognition and Learning, 2(2), 177-183.

Volet, S., Vauras, M., \& Salonen, P. (2009). Self and social regulation in learning contexts: An integrative perspective. Educational Psychologist, 44(4), 215-226.

Winne, P. H., Hadwin, A. F., \& Gress, C. L. Z. (2010). The learning kit project: Software tools for supporting and researching regulation of collaborative learning. Computers in Human Behavior, 26(5), 787-793. 